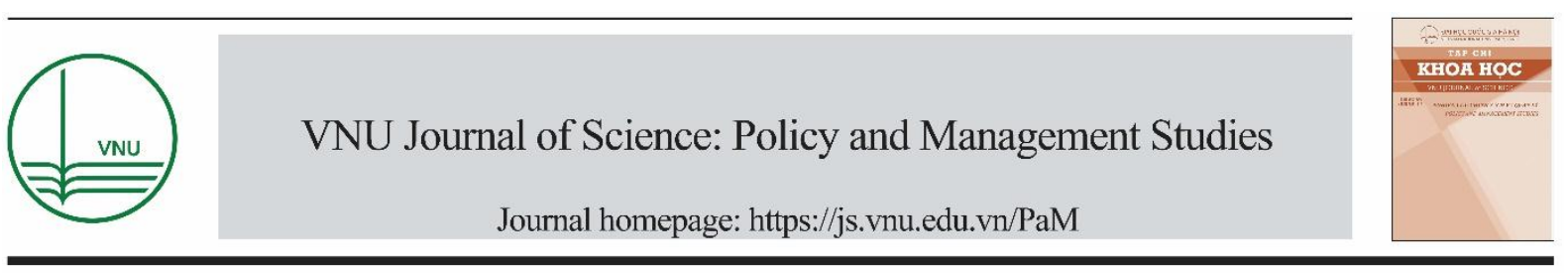

Review Article

\title{
Policies to Promote Angel Investment in Startups in Some Countries in Southeast Asia
}

\author{
Nguyen Thi Kim Anh ${ }^{1, *}$, Dang Thanh Dat ${ }^{2}$ \\ ${ }^{1}$ University of Economics and Business, Vietnam National University, Hanoi, \\ 144 Xuan Thuy, Cau Giay, Hanoi, Vietnam \\ ${ }^{2}$ Centre for Enabling Startups and Knowledge Transfer, Vietnam National University, Hanoi, \\ 144 Xuan Thuy, Cau Giay, Hanoi, Vietnam
}

Received 03 September 2020

Revised 23 November 2020; Accepted 26 November 2020

\begin{abstract}
Angel investor plays an important role in the startup ecosystem, and is a factor that fills the capital gap for startups and also brings many benefits to startups when they can accompany and support expertise, management and consulting for startups. In the early stage of establishment and development of the startup ecosystem, the role of governments was important in issuing policies and providing solutions to promote angel investment. For Vietnam, encouraging angel investors to invest in startups is an important policy in developing the startup ecosystem. With research on policies to promote angel investment in startups in some countries in Southeast Asia including: Singapore, Thailand and Malaysia, the article summarizes some experiences to promote angel investment in startups in Vietnam.
\end{abstract}

Keyword: angel investor, startup.

\footnotetext{
${ }^{*}$ Corresponding author.

Email address: pmduc86@yahoo.com
}

https://doi.org/10.25073/2588-1116/vnupam.4263 


\title{
Chính sách thúc đẩy đầu tư thiên thần vào startup tại một số quốc gia trong khu vực
}

\author{
Nguyễn Thị Kim Anh ${ }^{1, *}$, Đặng Thành Đạt ${ }^{2}$ \\ ${ }^{1}$ Truoòng Đại học Kinh tế, Đại học Quốc gia Hà Nội, 144 Xuân Thủy, Cầu Giấy, Hà Nội, Việt Nam \\ ${ }^{2}$ Trung tâm Chuyển giao Tri thức và Hỗ trọ Khởi nghiệp, Đại học Quốc gia Hà Nội \\ 144 Xuân Thủy, Cầu Giấy, Hà Nội, Việt Nam \\ Nhận ngày 03 tháng 09 năm 2020 \\ Chỉnh sửa ngày 23 tháng 11 năm 2020; Chấp nhận đăng ngày 26 tháng 11 năm 2020
}

\begin{abstract}
Tóm tắt: Nhà đầu tư thiên thần đóng vai trò quan trọng trong hệ sinh thái startup, là nhân tố lấp đầy khoảng trống vốn cho startup và cũng mang lại nhiều lợi ích cho startup khi có thể đồng hành, hỗ trợ về chuyên môn, quản lý và cố vấn cho startup. Trong giai đoạn sơ khai hình thành và phát triển hệ sinh thái startup, Chính phủ các nước có vai trò quan trọng trong việc ban hành các chính sách và đưa ra các giải pháp thúc đẩy đầu tư thiên thần cả trong và ngoài nước vào startup tại quốc gia. Đối với Việt Nam, việc khuyến khích các nhà đầu tư thiên thần đầu tư vào các startup là chính sách quan trọng trong phát triển hệ sinh thái startup tại Việt Nam. Với việc nghiên cứu chính sách thúc đẩy đầu tư thiên thần vào startup tại một số quốc gia trong khu vực gồm có: Singapore, Thái Lan và Malaysia, bài viết đúc kết một số kinh nghiệm để thúc đẩy đầu tư thiên thần vào startup tại Việt Nam

Tù khóa: đầu tư thiên thần, angel investor, startup.
\end{abstract}

\section{Mở đầu}

Nhà đầu tư thiên thần là người có giá trị tài sản đầu tư lớn, hỗ trợ tài chính cho các doanh nghiệp khởi nghiệp với mục đích thường là đổi lấy quyền sở hữu vốn và các hình thức chuyển đổi khác trong công ty [1]. Những nhà đầu tư thiên thần hầu hết đều là những người đi trước, đã có kinh nghiệm trong một hay nhiều lĩnh vực khác nhau. Họ không chỉ cấp vốn mà còn là người đồng hành trong vai trò hỗ trợ về chuyên môn, quản lý và cố vấn cho startup, giúp các startup dựa trên những kinh nghiệm và mạng lưới quan hệ mà các nhà đầu tư thiên thần đã có. Trong giai đoạn phát triển ban đầu của startup, vốn đầu tư thiền thần là bước đệm giữa giai đoạn hạt giống (seed) và giai đoạn startup đã định hình nhưng cần số vốn lớn để tăng trưởng nhanh (early stage), khi các Quỹ đầu tư mạo hiểm thường không đầu tư cho startup khi còn quá nhỏ.

Với vai trò quan trọng của đầu tư thiên thần với startup, Chính phủ các quốc gia, thường chú trọng tới các chính sách thúc đẩy đầu tư thiên thần vào startup. Tại các nước phát triển như Mỹ, Anh có số lượng lớn các nhà đầu tư thiên thần; họ đầu tư vào rất nhiều các lĩnh vực khác nhau từ y tế, bảo hiểm, công nghệ, khoa học, trí tuệ nhân tạo,... Hiện nay, trên thế giới đang có ngày càng nhiều các hiệp hội liên kết các nhà đầu tư thiên thần, được sự hỗ trợ từ chính sách của Chính phủ các quốc gia.

\footnotetext{
*Tác giả liên hệ.

Địa chi email: pmduc86@yahoo.com

https://doi.org/10.25073/2588-1116/vnupam.4263
} 
Tại khu vực Đông Nam Á, một số quốc gia như Singapore, Thái Lan và Malaysia có hoạt động đầu tư thiên thần tương đối sôi động, trong đó Chính phủ các quốc gia này đã ban hành nhiều chính sách thúc đẩy đầu tư thiên thần, có thể nghiên cứu để đúc kết kinh nghiệm cho Việt Nam - quốc gia mới xây dựng hệ sinh thái startup.

\section{Chính sách thúc đẩy đầu tư thiên thần vào startup tại Singapore}

Singapore là đất nước có mật độ dân số chưa tới 6 triệu người, tuy nhiên có tới trên 3.300 statup đang hoạt động [2] và được đánh giá là hệ sinh thái startup lớn nhất Châu Á, trung tâm khởi nghiệp ở khu vực Đông Nam Á với hơn 400 nhà đầu tư thiên thần chính thức, 143 Vườn ươm khởi nghiệp (Incubator) và Tổ chức tăng tốc khởi nghiệp (Accelerator), trên 50 Văn phòng làm việc chung (Co-working space) hoạt động [2]. Hầu như các Quỹ đầu tư mạo hiểm (Venture Capital) lớn trên thế giới đều có văn phòng tại Singapore, nhắm đến đầu tư vào các startup có trụ sở tại Singapore.

Các chương trình hỗ trợ startup ở Singapore không chỉ tạo ra động lực để khuyến khích giới trẻ ở Singapore khởi nghiệp mà còn thu hút nhân tài, đặc biệt trong lĩnh vực công nghệ trên toàn thế giới tới Singapore để khởi nghiệp. Phần lớn các chương trình đều tập trung vào việc hỗ trợ tài chính trực tiếp hoặc gián tiếp từ Chính phủ cho các startup [3]. Kết quả khảo sát tại Singapore đã xếp hạng chính sách hỗ trợ doanh nghiệp khởi nghiệp là một trong những điều kiện đầu tiên thu hút bất kỳ một nhà đầu tư nào vào thị trường Singapore. Bên cạnh việc ban hành những chính sách hỗ trợ startup, chính phủ Singapore cũng có một số chương trình hỗ trợ và chính sách khuyến khích nhằm thu hút đầu tư thiên thần tại Singapore.

(1) Chính phủ Singapore có chính sách hỗ trợ đầu tư cho nhà đầu tư thiên thần, theo đó nhà đầu tư thiên thần chỉ phải đóng góp một nửa thay vì toàn bộ số vốn đầu tư cho startup; một nửa còn lại sẽ được tài trợ theo Chương trình Phát triển
Startup (SEEDS Capital) do Ban Phát triển kinh tế (EDB) triển khai từ năm 2000, sau đó chuyển giao cho Cơ quan hỗ trợ doanh nghiệp của Singapore (SPRING) năm 2008 [4]. Năm 2018, Chính phủ Singapore sáp nhập SPRING và Cơ quan quản lý doanh nghiệp Quốc tế Singapore (International Enterprise Singapore) thành $\mathrm{Co}$ quan quản lý doanh nghiệp Singapore (Enterprise Singapore) với mục tiêu trọng tâm là hỗ trợ doanh nghiệp Singapore - từ doanh nghiệp khởi nghiệp, doanh nghiệp vừa và nhỏ đến các tập đoàn lớn của Singapore, thúc đẩy đổi mới công nghệ, phát minh sáng chế, giúp doanh nghiệp xây dựng chính sách phát triển vươn tầm quốc tế. Hiện nay có khoảng 500 nhà đầu tư và trên 40 Vườn ươm khởi nghiệp (Incubator) và Tổ chức tăng tốc khởi nghiệp (Accelerator), Quỹ đầu tư mạo hiểm tham gia chương trình SEEDS Capital của Enterprise Singapore [5].

(2) Năm 2010, Chính phủ Singapore ban hành chính sách giảm trừ thuế cho nhà đầu tư thiên thần có tên gọi Giảm thuế cho Nhà đầu tư thiên thần (Angel Investors Tax Deduction Scheme - AITD) có thời gian thực hiện 10 năm (tới năm 2020). Theo chính sách này, nhà đầu tư thiên thần chính thức (approved angel investor) đầu tư tối thiểu 100.000 đôla Singapore vào startup ở Singapore sẽ được giảm thuế, tùy vào lượng tiền đầu tư sẽ được mức giảm tối đa 250.000 đôla Singapore mỗi năm. Để đủ điều kiện nhận ưu đãi này, nhà đầu tư thiên thần phải được cồng nhận bởi Enterprise Singapore [6].

(3) Chính phủ Singapore tạo điều kiện để các nhà đầu tư thiên thần ở Singapore liên kết với nhau và thiết lập các mạng lưới nhà đầu tư thiên thần. Năm 2001, Mạng lưới Nhà đầu tư thiên thần Đông Nam Á (Business Angel Network of Southeast Asia - BANSEA) được một nhóm các nhà đầu tư thiên thần thành lập tại Singapore, mở rộng kết nối tới các nhóm đầu tư ở Thái Lan, Malaysia, Việt Nam và Indonesia. BANSEA đưa ra tầm nhìn phát triển một cộng đồng đầu tư thiên thần chuyên nghiệp ở Singapore thông qua chia sẻ kiến thức, hợp tác đầu tư giữa các nhà đầu tư cũng như gia tăng kết nối giữa nhà đầu tư và doanh nghiệp startup. BANSEA có nhiệm vụ thúc đẩy hệ thống startup mà ở đó nhà đầu tư 
thiên thần cung cấp vốn cho các doanh nghiệp, sau đó bản thân các doanh nghiệp này lại tiếp tục trở thành nhà đầu tư thiên thần cho các doanh nghiệp khác [4]. Ngoài BANSEA, Singapore còn có rất nhiều mạng lưới nhà đầu tư thiên thần khác với sự hỗ trợ tích cực từ Chính phủ Singapore.

Tóm lại, để thúc đẩy đầu tư thiên thần vào startup, Singapore có 3 nhóm chính sách chính: 1) Chính sách về tổ chức hành chính với việc giao cho một đơn vị chuyên trách hỗ trợ cho startup, trong đó có nhiệm vụ thu hút đầu tư thiên thần theo chủ trương của Chính phủ; 2) Chính sách giảm thuế cho nhà đầu tư thiên thần để khuyến khích đầu tư; 3) Tạo điều kiện cho mạng lưới đầu tư thiên thần hoạt động một cách chuyên nghiệp, theo đúng quy định của quốc gia.

\section{Chính sách thúc đẩy đầu tư thiên thần vào startup tại Thái Lan}

Bảng số liệu về đầu tư vào startup tại Thái Lan

\begin{tabular}{|l|c|c|c|}
\hline \multicolumn{1}{|c|}{ Loại hình } & $\begin{array}{c}\text { Năm } \\
2012\end{array}$ & $\begin{array}{c}\text { Năm } \\
2015\end{array}$ & $\begin{array}{c}\text { Năm } \\
2018\end{array}$ \\
\hline $\begin{array}{l}\text { Số lượng Quỹ đầu tư } \\
\text { mạo hiểm }\end{array}$ & 1 & 56 & 110 \\
\hline $\begin{array}{l}\text { Số lượng Nhà đầu tư } \\
\text { thiên thần }\end{array}$ & 2 & 30 & 50 \\
\hline $\begin{array}{l}\text { Số lượng Tổ chức } \\
\text { thúc đầy kinh doanh }\end{array}$ & 1 & 5 & $>8$ \\
\hline $\begin{array}{l}\text { Số lượng startup } \\
\text { nhận được đầu tư } \\
\text { trong năm }\end{array}$ & 2 & 27 & 102 \\
\hline
\end{tabular}

Nguồn: Startup Ecosystem Thailand [8],

Thái Lan là thị trường với nhiều cơ hội cho các doanh nghiệp khởi nghiệp ở Đông Nam Á. Đây là nền kinh tế lớn thứ hai trong khu vực và có một số chính sách thân thiện cho các nhà đầu tư [7]. Trong những năm qua, hệ sinh thái startup Thái Lan phát triển tương đối mạnh mẽ với trên 600 startup đang hoạt động (dân số Thái Lan gần 70 triệu người), số lượng nhà đầu tư thiên thần chính thức tăng từ 2 (năm 2012) lên 30 (năm 2015 ) và 50 (năm 2018), đặc biệt $57 \%$ trong số đó là nhà đầu tư thiên thần nước ngoài. Năm 2012 ở Thái Lan chỉ có 2 startup nhận được nguồn vốn đầu tư thì đến năm 2015 đã có 27 startup được đầu tư và đến năm 2018 có 102 startup được đầu tư.

Tại Thái Lan, vốn đầu tư mạo hiểm và vốn đầu tư thiên thần kinh doanh là hai nguồn vốn đầu tư chủ đạo hỗ trợ cho startup. Chính phủ Thái Lan đã có một số hoạt động thu hút đầu tư thiên thần nước ngoài.

(1) Cơ quan phát triển khoa học và công nghệ quốc gia Thái Lan (National Science and Technology Development Agency - NSTDA) thuộc Chính phủ hợp tác với Diễn đàn Nhà đầu tư thiên thần thế giới (The World Business Angels Investment Forum - WBAF) để tạo dựng cộng đồng các nhà đầu tư thiên thần cho các startup trong nước.

(2) Năm 2018, Chính phủ Thái Lan thông qua luật về ưu đãi thuế (Tax Incentive) cho nhà đầu tư thiên thần đầu tư vào statup tại Thái Lan. Nhà đầu tư thiên thần phải được công nhận bởi Cơ quan phát triển khoa học và công nghệ quốc gia Thái Lan (NSTDA) [9]. Theo luật ưu đãi thuế, nhà đầu tư thiên thần có thể được giảm thuế thu nhập cá nhân tối đa 100.000 Thai Baht (THB) mỗi năm. Nhà đầu tư thiên thần cần đáp ứng một số điều kiện ràng buộc như đầu tư vào một số lĩnh vực ưu tiên, giữ cổ phần của startup trong tối thiểu 2 năm liên tiếp kể từ thời điểm đầu tư mới được hưởng chính sách ưu đãi thuế.

(3) Thái Lan là nước đi sau trong quá trình công nghiệp hóa với ngành chủ chốt gồm nông nghiệp, ô tô, dịch vụ, tài chính; tuy nhiên trong những năm gần đây Chính phủ Thái Lan đã thực hiện chiến lược kinh tế mới với các chính sách thúc đẩy các doanh nghiệp vừa và nhỏ đầu tư đổi mới công nghệ, đồng thời tạo môi trường thuận lợi hơn để thu hút các nhà đầu tư, gồm cả nhà đầu tư thiên thần vào các startup, đặc biệt là startup liên quan đến đổi mới công nghệ để Thái Lan có thể phát triển thành các hub công nghệ. Do đó, Chính phủ Thái Lan khuyến khích các startup tập trung chủ yếu vào các lĩnh vực liên quan đến công nghệ, đặc biệt là công nghệ cao. Từ chính sách ưu tiên của Chính phủ, các nhà 
đầu tư thiên thần đầu tư vào startup ở Thái Lan là từ nhu cầu thực tiễn và sẽ giúp cho nền kinh tế Thái Lan phát triển mạnh mẽ hơn về công nghệ. Các lĩnh vực startup thu hút được nhiều nhất vốn đầu tư ở Thái Lan những năm gần đây là thương mại điện tử, logistics, công nghệ tài chính (fintech), thanh toán và nhà hàng, ăn uống.

Nhìn chung, Thái Lan đã thực thi một số chính sách để thúc đẩy đầu tư thiên thần vào startup: 1) Chính sách về tổ chức hành chính với việc giao cho một đơn vị chuyên trách hỗ trợ cho startup, trong đó có nhiệm vụ thu hút đầu tư thiên thần theo chủ trương của Chính phủ; 2) Chính sách ưu đãi thuế cho nhà đầu tư thiên thần để khuyến khích đầu tư. 3) Chính sách lựa chọn lĩnh vực ưu tiên thu hút vốn đầu tư thiên thần.

\section{Chính sách thúc đẩy đầu tư thiên thần vào startup tại Malaysia}

Tại Malaysia, một số cơ quan thuộc chính phủ Malaysia được chỉ định để hỗ trợ các startup cho đến khi tăng trưởng và trở thành các công ty lớn. Tuy nhiên, phần lớn các startup tại Malaysia lựa chọn liên kết với một trường đại học hoặc các viện nghiên cứu để được nhận nguồn trợ cấp nghiên cứu từ chính phủ. Theo một nghiên cứu với 28 startup công nghệ tại Malaysia năm 2015 [10], có $31 \%$ startup được tài trợ thông qua các nguồn vốn đầu tư của công ty đầu tư tài chính nhà nước, tiếp theo là các khoản tài trợ của chính phủ (27\%), trong khi chỉ có $3 \%$ nhận vốn đầu tư từ nhà đầu tư thiên thần. Điều đó cho thấy sự tham gia của nhà đầu tư thiên thần vẫn ở mức thấp ở Malaysia, trong khi quỹ đầu tư công vẫn chiếm ưu thế trong các quỹ đầu tư trong nước. Tuy nhiên, Malaysia đã có những chính sách và biện pháp để thúc đẩy đầu tư thiên thần vào startup.

(1) Ý tưởng về một cơ quan đại diện cho các nhà đầu tư tư nhân lần đầu được Chính phủ Malaysia khởi xướng vào năm 2010 nhằm nồ lực giải quyết tài trợ cho các startup bằng huy động vốn. Năm 2012, tại Diễn đàn Thiên thần kinh doanh Châu Á, Malaysia, Quỹ Cradle Sdn Bhd Cradle, cơ quan thuộc Bộ Tài chính công bố thành lập Mạng lưới các Nhà đầu tư thiên thần Malaysia (Malaysian Business Angels Network - MBAN) với tầm nhìn trở thành tiểng nói chính thức cho cộng đồng đầu tư thiên thần Malaysia, trở thành Quỹ đầu tư thiên thần lớn mạnh và là nơi giao lưu và chia sẻ kiến thức cho các nhà đầu tư thiên thần trong nước, trong khu vực và quốc tế. MBAN được Bộ Tài chính Malaysia ủy quyền trong việc công nhận Nhà đầu tư thiên thần cho Chương trình Uu đãi Thuế nhà đầu tư thiên thần và các chương trình liên quan khác thuộc phạm vi Bộ Tài chính. MBAN cũng có trách nhiệm xác nhận các nhà đầu tư thiên thần và các câu lạc bộ nhà đầu tư thiên thần, xây dựng nhận thức và đào tạo cho nhà đầu tư thiên thần cũng như giám sát các số liệu đầu tư thiên thần tại Malaysia. MBAN là một thực thể có chức năng như là một tổ chức thương mại điều khiển các liên kết giữa các nhà đầu tư thiên thần trong và ngoài nước.

Tính đến hết 2018, MBAN đã công nhận 240 nhà đầu tư thiên thần, gồm các nhà đầu tư trong 10 câu lạc bộ nhà đầu tư thiên thần lớn tại Malaysia và các nhà đầu tư tự do cả trong và ngoài nước. Từ năm 2015 đến 2018, MBAN đã đầu tư vốn cho 65 startup trong gần 350 startup thuyết trình gọi vốn (pitching) [11].

(2) Năm 2013, Chính phủ Malaysia công bố Uu đãi thuế cho nhà đầu tư thiên thần (Angel Tax Incentive - ATI) trong nguồn ngân sách quốc gia với ưu đãi thuế quy định mức giảm lên đến 500,000 RM mỗi năm. ATI được quản lý bởi Văn phòng ưu đãi thuế thiên thần (Angel Tax Incentive Office - ATIO), một đơn vị của quỹ Cradel. Để đủ điều kiện nhận ưu đãi này, nhà đầu tư thiên thần phải được $\mathrm{MBAN}$ công nhận và được xác nhận bởi Bộ Tài chính Malaysia. Sau 2 năm để từ khi đầu tư, nhà đầu tư thiên thần có thể trình thuế thu nhập cá nhân thông qua cơ quan thực hiện xử lý cắt giảm thuế có tên Lemgaba Hasil Dalam Negeri (LHDN) [12,13].

Như vậy, để thúc đẩy đầu tư thiên thần vào startup, Malaysia có 2 nhóm chính sách chính: 1) Chính sách ưu đãi thuế cho nhà đầu tư thiên thần để khuyến khích đầu tư; 2) Ủng hộ và tạo điều kiện cho mạng lưới đầu tư thiên thần hoạt động như là một tổ chức thương mại liên kết giữa các 
nhà đầu tư thiên thần trong và ngoài nước để đầu tư cho startup tại quốc gia.

\section{Kinh nghiệm để thúc đẩy đầu tư thiên thần vào startup tại Việt Nam}

Tại Việt Nam, hoạt động đổi mới sáng tạo và khởi nghiệp bắt đầu được chú trọng đặc biệt trong những năm gần đây. Năm 2017, Chính phủ ban hành Đề án "Hỗ trợ hệ sinh thái khởi nghiệp đổi mới sáng tạo quốc gia đến năm 2025". Năm 2018, Chính phủ ban hành Nghị định 38/2018/NĐ-CP đầu tư cho doanh nghiệp nhỏ và vừa khởi nghiệp sáng tạo có quy định về Quỹ đầu tư khởi nghiệp sáng tạo. Cùng với sự hình thành của hệ sinh thái khởi nghiệp tại Việt Nam, hoạt động của nhà đầu tư thiên thần trong nước và ngoài nước cũng dần được tạo lập; tuy nhiên cần các chính sách và giải pháp từ Chính phủ để thúc đẩy đầu tư thiên thần vào startup.

Thông qua nghiên cứu các chính sách thúc đẩy đầu tư thiên thần vào startup tại một số quốc gia trong khu vực, có thể đúc kết một số kinh nghiệm để thúc đẩy đầu tư thiên thần vào startup tại Việt Nam như sau:

(1) Nên tạo cơ chế khuyến khích thành lập mạng lưới các nhà đầu tư thiên thần, hoạt động có sự giám sát của Nhà nước nhằm tập hợp các nhà đầu tư trong nước và ngoài nước có vốn và kinh nghiệm để đầu tư, đồng hành, hướng dẫn cho các startup. Hình thành mạng lưới đầu tư thiên thần cũng giúp cho các nhà đầu tư thiên thần liên kết các nguồn lực về tài chính, chuyên môn và thông tin để đầu tư vào startup một cách hiệu quả.

(2) Giao cho một cơ quan thuộc Chính phủ chủ trì thực hiện những giải pháp được Chính phủ đưa ra để thúc đẩy đầu tư thiên thần vào startup. Cơ quan này đóng một số vai trò như công nhận nhà đầu tư thiên thần, thực thi chính sách hỗ trợ đầu tư cho nhà đầu tư thiên thần, giám sát hoạt động của mạng lưới đầu tư thiên thần và nhà đầu tư thiên thần, tổ chức sự kiện kết nối và tạo dựng cộng đồng các nhà đầu tư thiên thần,...
(3) Có chính sách ưu đãi dành cho nhà đầu tư thiên thần khi đầu tư vào startup nhằm mục đích thu hút các nhà đầu tư tiềm năng tham gia đầu tư. Các chính sách nên được thực hiện là: ưu đãi, giảm thuế thu nhập cá nhân đối với các khoản đầu tư của nhà đầu tư thiên thần, đối ứng vốn, cùng đầu tư vốn cho startup.

(4) Tại Việt Nam, hiện chưa có văn bản pháp luật định nghĩa cụ thể thế nào là một nhà đầu tư thiên thần, chưa có khung pháp lý nhằm bảo vệ quyền lợi của nhà đầu tư thiên thần, do vậy chưa khuyến khích được nhà đầu tư thiên thần tham gia đầu tư. Trước mắt nên luật hóa khái niệm nhà đầu tư thiên thần để công nhận chính thức chủ thể quan trọng với sự phát triển của startup và hướng tới quy định cụ thể quyền lợi của nhà đầu tư thiên thần để khuyến khích các hoạt động đầu tư thiên thần như các quốc gia đã thực hiện thành công.

(5) Các chính sách hỗ trợ từ Chính phủ để startup phát triển là một trong những điều kiện thu hút đầu tư vào startup. Chính phủ đóng vai trò phát triển hệ sinh thái startup, hỗ trợ, đồng hành, tạo môi trường để startup phát triển. Do vậy, chú trọng vào nghiên cứu, ban hành các chính sách để hỗ trợ các startup có điều kiện phát triển cũng góp phần quan trọng để thúc đẩy đầu tư thiên thần vào startup tại Việt Nam.

\section{Kết luận}

Nhà đầu tư thiên thần là nhân tố quan trọng trong hệ sinh thái startup. Chính vì vậy, chính sách khuyến khích các nhà đầu tư thiên đầu tư vào các dự án khởi nghiệp là cần thiết trong phát triển hệ sinh thái startup tại các quốc gia. Đối với quốc gia có hệ sinh thái startup mới phát triển như Việt Nam, vai trò của Nhà nước là quan trọng với việc thúc đẩy hoạt động đầu tư thiên thần, trong đó Chính phủ và các cơ quan quản lý nhà nước cần thực hiện nhiều chính sách và giải pháp thúc đẩy sự phát triển của hoạt động đầu tư thiên thần nói chung, các nhà đầu tư thiên thần nói riêng. Kinh nghiệm thực tiễn từ một số quốc gia trong khu vực đã và đang thực hiện thành công thúc đẩy đầu tư thiên thần vào startup như 
Singapore, Thái Lan và Malaysia đã trình bày trong bài viết là những bài học tham khảo có thể nghiên cứu, áp dụng tại Việt Nam.

\section{Tài liệu tham khảo}

[1] Investopedia, Angel Investor, https://investopedia.com/terms/a/angelinvestor.as, 2020 (accessed on 03/9/2020).

[2] Startup SG, Overview Singapore's Startup Ecosystem, https://www.startupsg.gov.sg/, 2020 (accessed on 03/9/2020).

[3] WTO and International Trade Center - VCCI, research report: Mechanism to support Innovative Startups: International Experience - Proposed solutions for Vietnam, https://wtocenter.vn/anpham/13265-study-mechanism-to-supportinnovative-startups-international-experience--proposed-solutions-for-vietnam, 2017 (accessed on 03/9/2020).

[4] Kam, W.P. Overview of angel investing in Singapore, Tech in Asia, https://www.techinasia.com/overview-of-angelinvesting-in-singapore/, 2011 (accessed on 03/9/2020).

[5] Enterprise Singapore, SEEDS Capital - Enterprise Singapore, https://www.enterprisesg.gov.sg/financialassistance/investments/investments/seedscapital/overview, 2020 (accessed on 03/9/2020).

[6] Guide Me Singapore, Singapore Tax Deduction Scheme for Angel Investors, https://www.guidemesingapore.com/business- guides/taxation-and-accounting/personal-tax/taxdeduction-scheme-for-angel-investors, $\quad 2020$ (accessed on 03/9/2020).

[7] Startup Angels, Bangkok Startup Angels, https://startupangels.com/market/bangkok/, 2017 (accessed on 03/9/2020).

[8] Embassy of the Kingdom of the Netherlands in Bangkok, Startup Ecosystem Thailand, www.nederlandenu.nl >startup-thailand-factsheet, 2019 (accessed on 03/9/2020).

[9] DFDL, Thailand Tax Update: New Tax Incentives for Angel Investors, Jonathan Blaine, https://www.dfdl.com/resources/legal-and-taxupdates/thailand-tax-update-tax-incentive-forangel-investor/, 2018 (accessed on 03/9/2020).

[10] Ajagbe Akintunde Musibau, Ismail Kamariah, The Financing of Early Staged Technology Based Firms in Malaysia, Middle-East Journal of Scientific Research (2013) 18 (5): 697-707, DOI: 10.5829/idosi.mejsr.2013.18.5.11747

[11] Malaysian Business Angels Network, 2018 Annual Report, https://mban.com.my/wp-content/uploads/ 2019/05/Annual-Report.pdf, 2019 (accessed on 03/9/2020).

[12] Malaysian Business Angels Network, Angel Tax Incentive, https://mban.com.my/angel-taxincentive/, 2020 (accessed on 03/9/2020).

[13] Malaysia Business Angel Network, Angel Investor Application Explanatory Notes and Guidance Note, https://mban.com.my/wpcontent/uploads/2017/04/Angel-Application_ Explanatory-Notes.pdf, 2017 (accessed on 03/9/2020). 